\title{
REAPROVEITAMENTO ENERGÉTICO DO LODO DE ESTAÇÃO DE TRATAMENTO DE ESGOTO - UMA REVISÃO
}

\section{REVIEW ENERGY REUSE OF SEWAGE TREATMENT PLANT SLUDGE}

\author{
A. F. F. MOURA ${ }^{1}$, A. M.O. SIQUEIRA ${ }^{2}$, I. C. LEITE ${ }^{3}$, M. C. MARTINS ${ }^{4}$, F. D. CASTRO ${ }^{5}$, J. L. da SILVA ${ }^{6}$
}

1 Universidade Federal de Viçosa, Departamento de Química; Viçosa/MG, Brasil; E-mail: anaflaviafmoura@hotmail.com; ORCID: https://orcid.org/0000-0001-5695-4362

2 Universidade Federal de Viçosa, Departamento de Química; Viçosa/MG, Brasil; E-mail: antonio.siqueira@ufv.br; ORCID: https://orcid.org/0000-0001-9334-0394

${ }^{3}$ Centro Universitário do Leste de Minas, Departamento de Engenharia Química, Coronel Fabriciano/MG, Brasil; Email: isabellacota.1@ gmail.com; ORCID: https://orcid.org/0000-0002-4688-2016

${ }^{4}$ Centro Universitário do Leste de Minas, Departamento de Engenharia Química; Coronel Fabriciano/MG, Brasil; E-mail: marcelacotam@gmail.com, ORCID: https://orcid.org/0000-0002-4284-0986

${ }^{5}$ Università degli Studi di Brescia; Brescia, Italy; E-mail: f.castro@ unibs.it, ORCID: https://orcid.org/00000001-7069-320X

${ }^{6}$ Centro Universitário do Leste de Minas, Departamento de Engenharia Química; Coronel Fabriciano/MG, Brasil; E-mail: lacerda_jaque@hotmail.com, ORCID: https://orcid.org/0000-0002-4776-4222

\begin{tabular}{|c|}
\hline A R T I C LE INFO \\
\hline $\begin{array}{l}\text { Article history: } \\
\text { Received 2019-01-29 } \\
\text { Accepted 2020-12-12 } \\
\text { Available online 2020-12-12 }\end{array}$ \\
\hline $\begin{array}{l}\text { palavras-chave } \\
\text { Lodo de ETE } \\
\text { Incineração de lodo } \\
\text { Pirólise de lodo }\end{array}$ \\
\hline $\begin{array}{l}\text { keywords} \\
\text { Sewage Treatment Plant sludge } \\
\text { Incineration of sludge } \\
\text { Pyrolysis of sludge }\end{array}$ \\
\hline
\end{tabular}

\begin{abstract}
A B S T R A C T
This work aimed to evaluate the capacity of the energy reuse of sludge from an urban sewage treatment plant (ETE), in order to determine the technical and economic viability of this final sludge destination, in comparison with the final disposal in landfill. The bibliographic analysis carried out shows that from an energetic point of view, the sludge from an urban sewage treatment plant, digested anaerobically, has a high organic load and a high calorific value in relation to other combustible biomasses. Therefore, its reuse can be economically and environmentally advantageous. The disposal of sludge in landfills, despite its simplicity, presents environmental problems, such as the possibility of contamination of groundwater, soil and emission of pollutants. The investigation shows that in the energy reuse, the processes of conversion of sludge into energy such as pyrolysis and incineration, presented satisfactory results, however they are processes of high cost of operation and maintenance.
R E S U M O
Este trabalho teve como objetivo avaliar a capacidade do reaproveitamento energético do lodo de uma estação de tratamento de esgoto (ETE) urbana, a fim de determinar a viabilidade técnica e econômica deste destino final do lodo, em comparação com a disposição final em aterro sanitário. A análise bibliográfica efetuada mostra que do ponto de vista energético, o lodo proveniente de uma ETE, digerido anaeróbio, possui elevada carga orgânica e elevado poder calorífico em relação a outras biomassas combustíveis. Sendo assim, seu reaproveitamento pode ser vantajoso econômica e ambientalmente. A disposição de lodo em aterros, apesar da simplicidade, apresenta problemas ambientais, como a possibilidade de contaminação do lençol freático, do solo e emissão de poluentes. A investigação mostra que no reaproveitamento energético, os processos de conversão do lodo em energia como pirólise e incineração, apresentaram resultados satisfatórios, porém são processos de elevados custos de operação e manutenção.




\section{INTRODUÇ̃̃̃O}

A necessidade do tratamento de esgotos sanitários é evidenciada pelo crescimento populacional e pela demanda cada vez maior por recursos naturais, resultando em um aumento gradativo da poluição ambiental. Esse tratamento gera um resíduo rico em matéria orgânica e nutrientes, denominado lodo de esgoto, cujas características dependem de diversos fatores, tais como a origem do efluente e o processo de tratamento do mesmo, que depois de tratado, deve ter uma correta destinação final (TSUTIYA e HIRATA, 2001;VANZETTO, 2012).

Os métodos convencionais de destino final do lodo de esgoto são: disposição em aterro sanitário, incineração, disposição superficial no solo e utilização na agricultura. A decisão pelo método mais viável vem se tornando uma problemática do processo de tratamento de esgoto, pois apesar do lodo representar apenas de 1 a $2 \%$ do volume do esgoto tratado, seu gerenciamento é bastante complexo e tem um custo geralmente entre 20 a $60 \%$ do total gasto com a operação de uma estação de tratamento de esgoto (VON SPERLING e FERNANDES, 2001; VIEIRA e ALEXANDRE, 2014).

Estudos recentes visando o reaproveitamento energético do lodo de uma estação de tratamento de esgoto (ETE) abrangem a obtenção de bio-óleo (processo de pirólise) e a incineração, destacando a sua utilização como boa fonte de energia em comparação às alternativas convencionais, evitando assim o seu descarte no meio ambiente (SILVA et al., 2005; ROMDHANA et al., 2009; VIEIRA et al., 2011).

O presente trabalho tem como objetivo a realização de um levantamento da composição e das características do lodo proveniente de estações de tratamento de esgoto doméstico, analisando a viabilidade técnica, econômica e ambiental dos processos de pirólise e incineração como alternativas sustentáveis para o reaproveitamento energético.

\section{CARACTERIZAÇÃO DO LODO DA ETE}

As características do lodo e sua composição química e física estão relacionadas diretamente com a origem do mesmo, ou seja, se é proveniente de uma área predominantemente residencial ou industrial, da época do ano, das condições socioeconômicas da população e da tecnologia utilizada no tratamento do esgoto (COSTA e COSTA, 2011).

Os processos de tratamento dos esgotos consistem em uma série de operações unitárias empregadas para a remoção de substâncias indesejáveis, ou para transformação destas substâncias em outras de forma aceitável. A remoção dos poluentes no tratamento, de forma a adequar o lançamento ao padrão de qualidade estabelecido pela legislação vigente, está associada aos conceitos de nível e eficiência do processo.

O tratamento dos esgotos em uma ETE é usualmente classificado através dos seguintes níveis: preliminar, primário, secundário e terciário. O tratamento preliminar objetiva, principalmente, a remoção de sólidos grosseiros e de areia, por meio de mecanismos básicos de ordem física. O tratamento primário destina-se, por meio de mecanismos básicos de ordem física, à remoção de sólidos flutuantes (graxas e óleos) e à remoção de sólidos em suspensão sedimentáveis e, em decorrência, de parte da matéria orgânica. Nesta etapa, pode ocorrer a adição de produtos químicos coagulantes. No tratamento secundário, predominam os mecanismos biológicos, cujo objetivo é, principalmente, a remoção de matéria orgânica $\mathrm{e}$, eventualmente, nutrientes (nitrogênio e fósforo). O tratamento terciário objetiva a remoção de poluentes específicos, ou ainda a remoção complementar de poluentes não suficientemente removidos no tratamento secundário (etapa facultativa) (VON SPERLING e FERNANDES, 2001).

O lodo de esgoto é constituído por vários grupos funcionais como ácidos, álcool, amina, nitrila, cetona e hidrocarbonetos, mas principalmente por grupos orgânicos como proteínas (40 a 60\%), carboidratos (25 a 50\%) e lipídeos (10\%), que mesmo após a digestão no tratamento, estarão presentes no lodo final. Essas estruturas orgânicas possuem elevado potencial energético e podem ser recuperadas em processos térmicos (WERTHER e OGADA, 1999; JORDÃO e PESSOA, 2005; VIEIRA e ALEXANDRE, 2014).

Em se tratando do lodo proveniente de esgoto doméstico, antes do processo de desidratação, sua composição média aponta para uma mistura de água $(99,9 \%)$ e sólidos $(0,1 \%)$, sendo que do total de sólidos, $70 \%$ são orgânicos (proteínas, carboidratos, gorduras, etc.) e 30\% inorgânicos (areia, sais, metais, etc.) (ANDREOLI, 1999).

A elevada concentração de matéria orgânica no lodo caracteriza a sua desestabilização, possibilidade de decomposição anaeróbia, putrefação, geração de odores e atração de vetores. A parcela desses compostos orgânicos é normalmente medida pela concentração ou pelo percentual de sólidos voláteis em relação aos sólidos totais (JORDÃO e PESSÔA, 2005).

A matéria inorgânica presente nos esgotos é formada, principalmente, por areia e substâncias minerais dissolvidas. A areia é proveniente de águas de lavagem das ruas e de águas de subsolo, que chegam às galerias de modo indevido ou que se infiltram através das juntas das canalizações. Raramente os esgotos são tratados para remoção de constituintes inorgânicos, salvo à exceção de alguns despejos industriais (ABREU, 1997; JORDÃO e PESSÔA, 2005).

Segundo Werther e Ogada (1999), as características físico-químicas do lodo de esgoto após o tratamento, diferem de região para região, porém em todos os casos apresentam um alto teor de água, que pode ser encontrada livre ou quimicamente ligada à partícula. Elas dependem do tipo de efluente utilizado, pois pode conter microrganismos ativos ou inativos e Substâncias Poliméricas Extracelulares (EPS), podendo essas serem ligadas a cátions.

Houdkova et al. (2008) evidenciam que elevados teores de hidrogênio e carbono contribuem de forma positiva com o poder calorífico do lodo, assim como uma menor constituição de água e oxigênio. A partir de suas análises, a composição imediata do lodo digerido anaerobiamente contém 49,2\%, $50,8 \%$ de cinzas, $65 \%$ de umidade e $12,2 \%$ de poder calorífico. 
Segundo Moreira (2013), as características químicas do lodo dependem de vários fatores que afetam a qualidade do lodo a ser utilizado. O conhecimento dessas características faz-se necessário para se definir uma melhor forma de destinação do lodo e prever os custos de cada etapa, pois essas têm influência direta nas etapas de tratamento do lodo, alterando assim na quantidade e qualidade do lodo gerado.

A forma de condicionamento do lodo e o tratamento para redução de patógenos, bem como os equipamentos utilizados pela ETE para esse fim, provocam alterações nas características do lodo, como pode-se observar na Tabela 1, que evidencia a diferença entre o lodo seco e o lodo compostado.

Tabela 1 - Componentes do Lodo de Esgoto.

\begin{tabular}{l|c|c|c}
\hline CARACTERÍSTICA & UNIDADE & SECO & COMPOSTADO \\
\hline PH & - & 8,3 & 7,3 \\
\hline UMIDADE & $\%(\mathrm{~m} / \mathrm{m})$ & 23 & 55 \\
\hline $\begin{array}{l}\text { CARBONO } \\
\text { ORGÂNICO }\end{array}$ & $\mathrm{g} \mathrm{kg}^{-1}$ & 264 & 303 \\
\hline NITROGÊNIO TOTAL & $\mathrm{g} \mathrm{kg}^{-1}$ & 39 & 23 \\
\hline FÓSFORO & $\mathrm{g} \mathrm{kg}^{-1}$ & 19 & 0,7 \\
\hline POTÁSSIO & $\mathrm{g} \mathrm{kg}^{-1}$ & 1,6 & 3,8 \\
\hline CÁLCIO & $\mathrm{g} \mathrm{kg}^{-1}$ & 12 & 7,4 \\
\hline MAGNÉSIO & $\mathrm{g} \mathrm{kg}^{-1}$ & 5,2 & 2,3 \\
\hline ENXOFRE & $\mathrm{g} \mathrm{kg}^{-1}$ & 7 & 2,6 \\
\hline ZINCO & $\mathrm{mg} \mathrm{kg}^{-1}$ & 734 & 373 \\
\hline COBRE & $\mathrm{mg} \mathrm{kg}^{-1}$ & 237 & 105 \\
\hline BORO & $\mathrm{mg} \mathrm{kg}^{-1}$ & 17 & 39 \\
\hline RELAÇÃO C/N & - & 7 & 13 \\
\hline \multicolumn{2}{c|}{ FONTE: Adaptado de SILVA ET AL., (2010). }
\end{tabular}

\section{PODER CALORÍFICO}

O conteúdo de energia química, ou poder calorífico, é um parâmetro importante quando se considera o processo de conversão de biomassa em energia, principalmente quando se trata de uma biomassa com elevada carga de material orgânico. Este parâmetro, mesmo se tratando de lodo de esgoto doméstico, depende da origem da biomassa e da composição da mesma, podendo apresentar diferentes valores para cada estação de tratamento de esgoto, que pode variar em torno de $0,1 \mathrm{MJ} / \mathrm{kg}$. (SPLITHOFF, 2010; SILVA, 2012).

Na Tabela 2 estão apresentados os valores de poder calorífico segundo alguns autores. Percebe-se que os valores oscilam entre 13,00 e 20,00 MJ/kg. Mesmo se tratando do mesmo material, esta variância não é incomum, uma vez que o poder calorífico do lodo está ligado com a porcentagem de matéria orgânica do mesmo. Esta propriedade varia para cada região, de acordo ao clima, a eficiência do processo de tratamento e as condições sócio econômicas da mesma.
Tabela 2 - Poder Calorífico do Lodo Anaeróbio.

\begin{tabular}{l|c|l}
\hline Material & $\begin{array}{c}\text { Poder } \\
\text { Calorífico } \\
\text { (MJ/kg) }\end{array}$ & Referência \\
\hline & 12,8 & $\begin{array}{l}\text { Von Sperling e Fernandes, } \\
2001 \\
\text { Ghini et al., 2007 } \\
\text { Lodo }\end{array}$ \\
$\begin{array}{l}\text { Digerido } \\
\text { Anaeróbio }\end{array}$ & 19,1 & Shimamura et al, 2008 \\
& 16,77 & Silva, 2012 \\
& 18,6 & Dweck et al, 2006 \\
& 13 & Andreothoff, 2010 1999 \\
\hline
\end{tabular}

FONTE: Própria (2019).

O poder calorífico é classificado em: Poder Calorífico Superior (PCS), que se refere ao conteúdo energético na base seca com umidade média de 50-60\%, ou seja, não se leva em consideração o calor associado à condensação da água formada em reação com o hidrogênio contido na biomassa e Poder Calorífico Inferior (PCI), o qual é obtido subtraindo do PCS o calor associado com a condensação do vapor de água formado pela reação do hidrogênio contido na biomassa, ou seja, se refere ao conteúdo energético na base úmida (OLIVEIRA, 2014).

A relação entre as principais biomassas utilizadas para geração de energia e outros tipos de lodo, também utilizados para este fim, e seu respectivo poder calorífico superior (PCS) e poder calorífico inferior (PCI) estão representados na Tabela 3.

Tabela 3 - Poder Calorífico das Principais Biomassas.

\begin{tabular}{l|c|c|l}
\hline Material & $\begin{array}{c}\text { PCS } \\
(\mathbf{M J} / \mathbf{K g})\end{array}$ & $\begin{array}{c}\text { PCI } \\
(\mathbf{M J} / \mathbf{K g})\end{array}$ & \multicolumn{1}{|c}{ Referência } \\
\hline Lodo de ETE & 20,1 & 18,6 & Borges et al., 2009 \\
\hline Lodo Têxtil & 17 & 15,4 & Borges et al., 2009 \\
\hline Lodo Celulose e Papel & 19,5 & 18 & Borges et al., 2009 \\
\hline Madeira Seca & 19,8 a & n/d & Oliveira et al., 2009 \\
\hline Madeira Úmida & 14,6 & n/d & Oliveira et al., 2009 \\
\hline Bagaço de Cana & 18 & 17 & Oliveira, 2014 \\
\hline Cavaco & 20,8 & 19,44 & Virmond et al., 2011 \\
\hline
\end{tabular}

FONTE: Própria (2019).

Na Tabela 3, observa-se que o lodo apresenta valores de PCS e PCI melhores que o bagaço de cana e um valor aproximado dos cavacos, que são comumente utilizados como biomassa combustível. Ou seja, o conteúdo energético do lodo de ETE é um indicativo da sua aplicabilidade como biomassa combustível na geração de energia. 


\section{PROCESSOS TÉRMICOS}

Pirólise

Os processos de pirólise, quando aplicados, têm como objetivo a obtenção de produtos com melhores propriedades e densidade energética elevada. Por isso, a pirólise tem sido considerada um método economicamente e ambientalmente viável para a eliminação de resíduos orgânicos, industriais e urbanos. É um processo de tratamento térmico em que o lodo (ou biomassa) é volatizado sob baixa pressão, na temperatura de $350-500^{\circ} \mathrm{C}$, na ausência completa de oxigênio. Nesse processo, o lodo é convertido em carvão, óleos de pirólise, vapor d'água e gases combustíveis. Parte dos sólidos e/ou produtos gasosos do processo de pirólise podem ser incinerados e usados como energia para aquecimento no próprio processo de pirólise. Nele, os principais fenômenos que ocorrem são: transferência de calor a partir de uma fonte de calor, ocasionando aumento da temperatura no interior do combustível; início das reações de pirólise, levando à liberação de compostos voláteis e a formação de resíduo carbonoso; liberação de compostos voláteis, resultando na transferência de calor entre os voláteis quentes e o combustível frio não pirolisado; condensação de alguns dos compostos voláteis nas partes mais frias do combustível para a produção de alcatrão e reações (VIEIRA et al., 2003; BABU, 2008; VASQUES, 2012).

No reator pirolítico, a matéria orgânica passa por uma série de etapas, como apresentado na Figura 1.

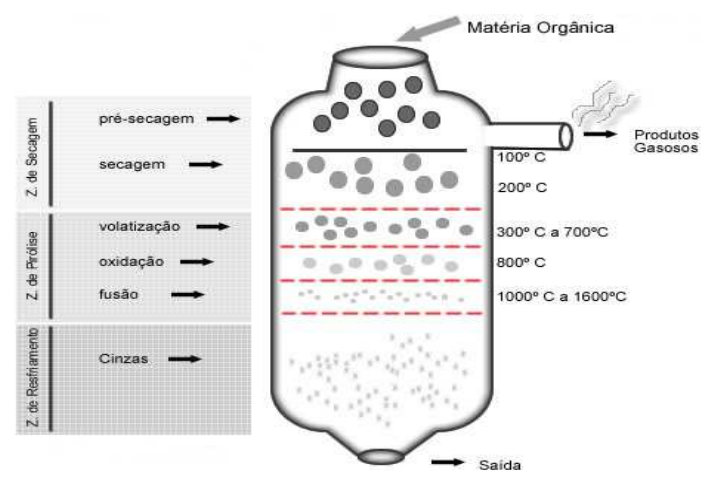

Figura 1 - Etapas do Reator Pirolítico

FONTE: Infoescola (2018).

Ao alimentar o reator, a matéria orgânica passa primeiramente pela zona de secagem, onde os resíduos que irão reator passar por duas etapas, a pré-secagem e a secagem propriamente dita. Nesta zona, as temperaturas estão em torno de 100 a $150^{\circ} \mathrm{C}$, sendo essa etapa de grande importância, pois se o processo não for bem executado, a umidade pode interagir com o processo gerando resultados impróprios. As reações do processo, sendo elas a volatização, oxidação e fusão, ocorrem na zona de pirólise, onde as temperaturas variam em torno de 150 a $1600^{\circ} \mathrm{C}$. Nesta fase também são coletados os produtos (álcoois, bio-óleo, alcatrão e entre outros). Por fim, os resíduos provenientes do processo são coletados na zona de resfriamento. Esses resíduos são char, cinzas e escória.

Segundo Santos (2013), algumas variáveis devem ser levadas em consideração, pois exercem influência sobre os rendimentos produzidos no processo de pirólise (frações sólidas, líquidas e gasosas). Esses parâmetros podem ser adequados de acordo com os objetivos preestabelecidos, gerando produtos diferenciados no final. As variáveis mais significativas no processo são as seguintes:

1) Temperatura de Permanência e Tamanho da Partícula: Estes dois fatores juntos, determinam a temperatura de reação em cada ponto do sólido. Com partículas de diâmetro superior a $10 \mathrm{~mm}$, sempre haverá aumento não desprezível de resistência para a transmissão de calor e para a elevação da temperatura. Como resultado disto, as partículas grandes pirolisam-se abaixo de $400^{\circ} \mathrm{C}$ (pirólise lenta). Para que as partículas possam ter em seu interior altas temperaturas, é necessário que tenham dimensões muito reduzidas. De fato, este fator (tamanho de partícula) define se a biomassa pode ser submetida ou não à pirólise rápida. Evidentemente, o tamanho da partícula também afeta o rendimento do carvão: quanto maior for a partícula, maior será o tempo de residência dos voláteis dentro da zona de calor (SÁNCHEZ et al., 2009).

2) Tempo de Residência: Na pirólise, o fator tempo de residência tem como importante relação a distribuição e características dos produtos obtidos. Isto é válido tanto para o sólido inicial, como para o material carbonáceo resultante e os produtos voláteis formados. Pequenos tempos de residência, como os empregados na pirólise rápida, não permitem a efetivação das reações secundárias, o que em geral produz aumentos no rendimento de carvão ou aumento em viscosidade da fração de alcatrão. O tempo de residência e a temperatura no reator determinam, em maior grau os resultados do processo de pirólise (SÁNCHEZ et al., 2009).

3) Vazão do Gás de Arraste: O efeito da vazão de gás de arraste diminui os tempos de residência dos vapores no reator, podendo atingir máxima produção de bio-óleo. Entretanto, uma rápida difusão dos vapores pelo fluxo de gás inerte interrompe as reações químicas que convertem a biomassa em produtos gasosos condensáveis (RODRIGUES et al., 2009).

A Tabela 4, apresenta o rendimento médio das frações obtidas no processo, de acordo com diferentes autores.

Tabela 4 - Rendimento de produtos da pirólise.

\begin{tabular}{c|c|c|c|c}
\hline $\begin{array}{c}\text { Matéria- } \\
\text { Prima }\end{array}$ & \multicolumn{3}{|c|}{ Frações (\%) } & Referências \\
\hline \multirow{4}{*}{$\begin{array}{c}\text { Lodo de } \\
\text { ETE }\end{array}$} & Líquida & Sólida & Gasosa & \\
\cline { 2 - 5 } & 26,7 & 56 & 17,3 & Pokorna et al. (2009) \\
\cline { 2 - 5 } & 38,24 & 59,07 & 13,36 & Surerus et al. (2014) \\
\cline { 2 - 5 } & 10,2 & 69,4 & 9,4 & Lutz et al. (2000) \\
\cline { 2 - 5 } & 13 & 47 & 22 & Sánchez et al. (2009) \\
\cline { 2 - 5 } & 11,6 & 61,2 & 13,7 & Sieira (2014) \\
\cline { 2 - 5 } & 14,7 & 58,2 & 14,1 & Silva (2012) \\
\hline
\end{tabular}

FONTE: Própria (2019).

A pirólise realizada na ausência de oxigênio, produz quatro frações: líquida aquosa, que contém uma grande variedade de compostos orgânicos solúveis; líquida orgânica, a qual contém compostos orgânicos de média e alta massa molecular; fração gasosa, também considerada como combustível, é composta de monóxido de carbono (CO), dióxido 
de carbono $\left(\mathrm{CO}_{2}\right)$, hidrocarbonetos leves, metano $\left(\mathrm{CH}_{4}\right)$ e hidrogênio molecular $\left(\mathrm{H}_{2}\right)$; fração sólida, que consiste principalmente em cinzas e carvão (dependendo da temperatura empregada no processo), e é o resíduo do processo que volatilizou. Os principais produtos gerados durante o processo de pirólise de biomassa são o bio-óleo (líquido), o carvão (sólido) e a fração gasosa. Devido ao fato de conterem um grande poder energético, esses materiais obtidos possuem uma vasta aplicabilidade (VIEIRA, 2000).

Os gases gerados ao longo do processo de pirólise possuem um alto poder calorífico. Esse calor pode ser utilizado para abastecer energeticamente a planta. A mistura de gases, gerada no processo de pirólise, é formada pelos componentes $\mathrm{CO}_{2}, \mathrm{CO}, \mathrm{CH}_{4}, \mathrm{H}_{2}$ e hidrocarbonetos de pequenas cadeias carbônicas C2 e C3 (SÁNCHEZ et al., 2009).

O bio-óleo tem sido usado com sucesso em caldeiras e tem mostrado potencial para uso em motores a diesel e turbinas (BRIDGWATER, 2004). Um valor típico de poder calorífico do líquido da pirólise de biomassa é em torno de $17 \mathrm{MJ} / \mathrm{kg}$ dos quais $40-45 \%$ são representados por combustíveis à base de hidrocarbonetos.

A fração sólida, o carvão, um resíduo sólido bastante rico em carbono, pode ser utilizado para a produção de carvão ativado, sendo este um excelente composto empregado na adsorção de compostos inorgânicos e orgânicos. O carvão ativado é largamente utilizado na extração de metal, purificação de água e entre outros processos (MENEDEZ et al., 2003).

\section{Incineração}

$\mathrm{O}$ processo de incineração ocorre de $550^{\circ} \mathrm{C}$ a $950^{\circ} \mathrm{C}$, usualmente $800^{\circ} \mathrm{C}$, e transforma o lodo seco ou o lodo desidratado em cinzas ou lodo incinerado e tem a capacidade de reduzir significativamente o volume de resíduos e os organismos patogênicos presentes no lodo. Pode ser considerada uma etapa de tratamento do lodo, mas também pode ser considerada uma das alternativas de disposição final do resíduo. Para Geyer (2001), a incineração com emissões controladas causa menos problemas do que a simples disposição de resíduos no solo, ou mesmo que a queima de combustíveis.

A incineração é um método de tratamento que utiliza a decomposição térmica via oxidação, com o objetivo de tornar um resíduo menos volumoso, menos tóxico ou atóxico, ou ainda eliminá-lo. Essa técnica é altamente eficiente em termos de eliminação do lodo. É através da queima que se obtém uma maior redução do volume do lodo e ainda há a possibilidade da reutilização das cinzas resultantes na disposição industrial. Durante a incineração de biossólidos, a massa inicial é reduzida em até 5 vezes, restando apenas os sólidos fixos (ANDREOLI, 1999; GODOY, 2013; MARTINS et al., 2015).

Segundo Jordão e Pessôa (2005), a incineração tem como objetivo a queima de sólidos. A parcela dos sólidos totais volatilizada no processo de calcinação, em $\mathrm{mg} / \mathrm{L}$ (sólidos voláteis) é transformada em $\mathrm{CO}_{2}, \mathrm{H}_{2} \mathrm{O}$ e $\mathrm{SO}_{2}$ e os fixos (residuos sólidos retidos após a calcinação dos sólidos totais a $500^{\circ} \mathrm{C}$, em $\mathrm{mg} / \mathrm{L}$ ) em cinzas. A temperatura é elevada, da ordem de $1000^{\circ} \mathrm{C}$, podendo haver grande aproveitamento de energia, a partir da utilização dos gases quentes provenientes da queima para aquecimento dos digestores e para geração de vapor.
Em sistemas com incineradores, são importantes ao processo o controle odorífero e o conhecimento da composição e poder calorífico do lodo. Alguns parâmetros devem ser levados em consideração, para que haja melhor eficiência no processo, sendo eles, o controle da temperatura de combustão, o tempo de residência dos gases, a taxa de alimentação e as características do combustível, assim como o meio térmico utilizado (ANDREOLI, 1999).

O processo consiste na combustão completa do lodo desidratado em fornos de bandejas múltiplas, e em leitos fluidizados, demonstrados nas Figuras 2 e 3, respectivamente. É o processo mais praticado, não sendo necessária a digestão prévia do lodo (ao contrário, a digestão reduz a parcela de voláteis no lodo, requerendo então maior quantidade de combustível auxiliar) (JORDÃO e PESSÔA, 2005). As principais etapas do processo de incineração são apresentadas na Figura 4.

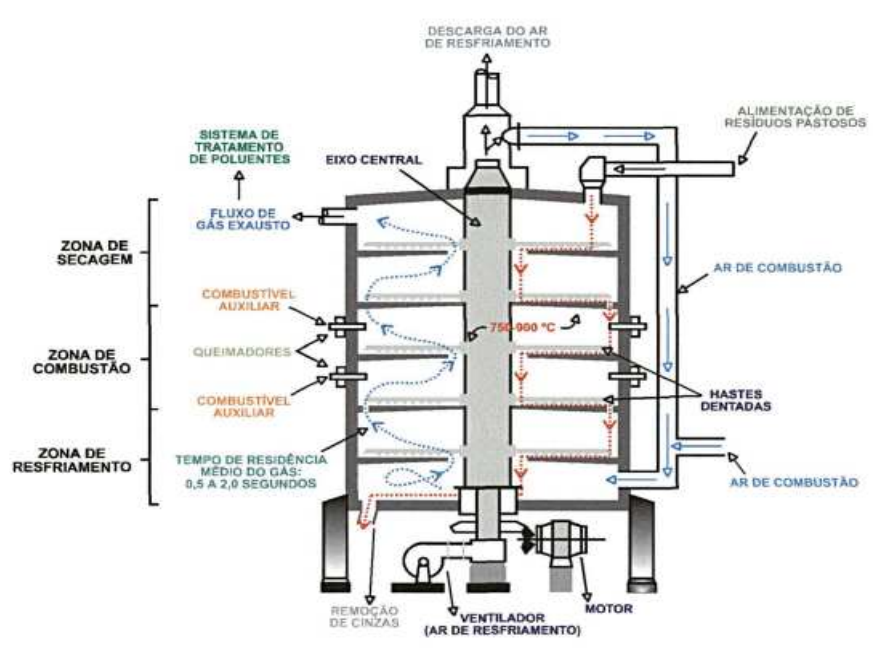

Figura 2 - Sistema incinerador de câmaras múltiplas FONTE: GUILHERME, 2000.

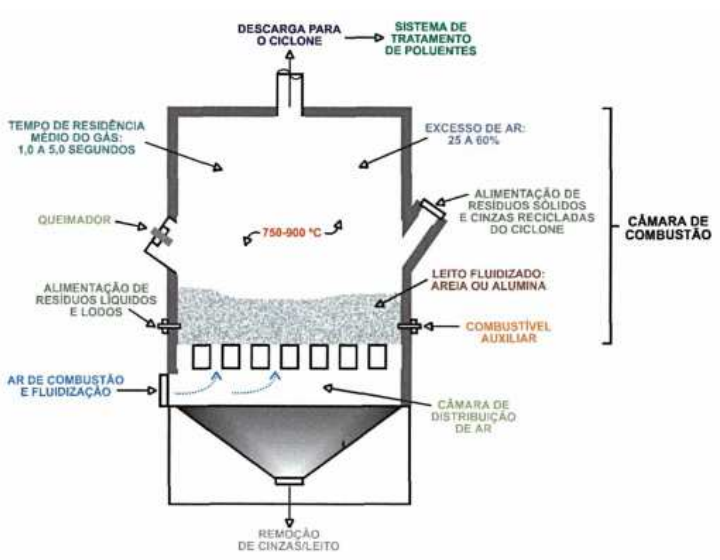

Figura 3 - Sistema incinerador de Leito fluidizado.

FONTE: GUILHERME, 2000. 


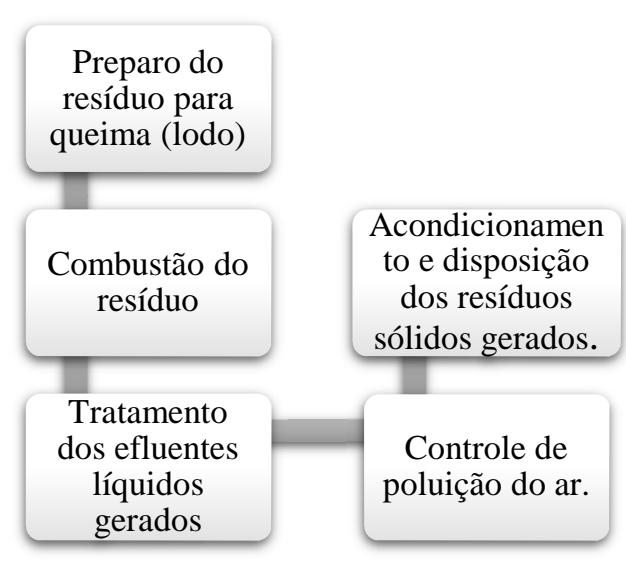

Figura 4 - Etapas do Processo de Incineração.

FONTE: Própria, 2019.

Através da análise dos dados da Tabela 5, relativos às emissões decorrentes da queima de resíduos urbanos, óleo diesel e carvão, conclui-se que os resíduos gerados no processo de incineração emitem gases em menor quantidade do que a queima de óleo diesel e carvão, que são processos utilizados com maior frequência.

Tabela 5 - Emissões decorrentes da queima de resíduos urbanos, óleo diesel e carvão para uma demanda de 2000 kWh.

\begin{tabular}{c|c|c|c}
\hline Emissão (kg/ano) & $\begin{array}{c}\text { Resíduo da } \\
\text { Incineração }\end{array}$ & $\begin{array}{c}\text { Óleo } \\
\text { diesel }\end{array}$ & Carvão \\
\hline Dióxido de Enxofre & 7,5 & 30 & 8 \\
\hline $\begin{array}{c}\text { Dióxido de } \\
\text { Nitrogênio }\end{array}$ & 7,5 & 30 & 8 \\
\hline Hidrogeno clorados & 1,0 & $*$ & 1 \\
\hline Poeira & 0,1 & 0,5 & 0,2 \\
\hline
\end{tabular}

FONTE: Adaptada de Geyer, 2001.

\section{CONCLUSÕES}

A fim de minimizar o problema de gestão final do lodo de uma ETE, várias formas de reaproveitamento do mesmo vêm sendo estudadas, valorizando-o como matéria-prima de inúmeros processos, dentre eles os processos térmicos estudados neste trabalho. O maior problema na disposição final do lodo é o crescente volume de produção.

Em face ao exposto, o processo de pirólise tem se mostrado uma alternativa ambientalmente correta a ser empregada no reaproveitamento dos lodos gerados nas ETEs, que se destaca devido à conversão do lodo em subprodutos com vasta aplicação, inclusive na geração de energia. As frações líquida e gasosa obtidas durante o processo apresentam elevados poderes caloríficos, que podem ser reaproveitados no próprio processo pirolítico. O resíduo sólido, gerado durante o processo, também pode ser reaproveitado na construção civil. Porém, esse processo exige uma sofisticada instalação de sistemas de lavagem dos gases resultantes.

O processo de incineração, por sua vez, é eficiente na redução do volume do lodo e valorização energética do mesmo. Em contraponto, apresenta a emissão de gases poluentes durante o processo semelhantes ao da pirólise, necessitando de controle ambiental das unidades, além do risco de contaminação de rios e aquíferos por vazamento de efluentes; poluição sonora decorrente do funcionamento do incinerador e problemas operacionais (a variabilidade da composição dos resíduos).

\section{R E F E R E N C I A S}

ABREU, M. F. Extração e determinação simultânea por emissão em plasma de nutrientes e elementos tóxicos em amostras de interesse agronômico. 1997. 68 f. Tese (Doutorado em Engenharia Ambiental) - Universidade Estadual de Campinas. São Paulo, 1997.

ANDREOLI, C. V. Uso e manejo do lodo de esgoto na agricultura e sua influência em características ambientais no agrossistema. 1999. 49 f. Tese (Doutorado em Meio Ambiente e Desenvolvimento) - Universidade Federal do Paraná, Curitiba, 1999.

BABU, B. V. Biomass pyrolysis: a state-of-the-art review. Biofuels, Bioproducts \& Biorefining, v. 2, n. 5, p. 393414, 2008.

BORGES, F.; SELLIN, N.; MEDEIROS, S. H. W. Caracterização e avaliação de lodos de efluentes sanitário e industrial como biomassa na geração de energia. Ciência \& Engenharia, v. 17, n. 1/2, p. 27-32, 2009.

BRIDGWATER, A.V. Biomass fast pyrolysis.Thermal Science, v. 8, n. 2, p. 21-49, 2004.

COSTA, A. N.; COSTA, A. F. S. Manual de uso agrícola e disposição do lodo de esgoto para o Estado do Espírito Santo. Vitória: Incaper, 2011. 126 p.

DWECK, J.; MORAIS, L. C.; MENESES, J. C.; BÜCHLER, P. M. Thermal analysis of municipal sludge waste combustion. In: Materials science forum. Trans Tech Publications, 2006. p. 740-746.

GEYER, A. L. B. Contribuição ao estudo da disposição final e aproveitamento da cinza de lodo de estações de tratamento de esgotos sanitários como adição ao concreto. 2001. 216 f. Tese (Doutorado em Engenharia Civil) - Universidade Federal do Rio Grande do Sul, Porto Alegre, 2001.

GHINI, R.; PATRÍCIO, F. R. A.; BETTIOL, W.; DE ALMEIDA, I. M. G.; MAIA, A. D. H. N. Effect of sewage sludge on suppressiveness to soil-borne plant pathogens. Soil Biology and Biochemistry, v. 39, n. 11, p. 2797-2805, 2007.

GODOY, L. C. A logística na destinação do lodo de esgoto. Revista Científica on-line-Tecnologia, Gestão e Humanismo, Guaratinguetá, v. 2, n. 1, p.79-90, nov. 2013.

GUILHERME, A. H. L. Estudo das reações durante a incineraçãode resíduos químicos - aspectos cinético e termodinâmico. 2000. 132 f. Dissertação ( Mestrado em Química)- Universidade Federal do Paraná. Curitiba, 2000.

HOUDKOVA, L.; BORAN, J.; UCEKAJ, V.; ELSÄSSER, T.; STEHLÍK, P. Thermal processing of sewage sludgeII. Applied Thermal Engineering, v. 28, n. 16, p. 20832088, 2008.

INFOESCOLA NAVEGANDO E APRENDENDO. Pirólise. Disponível em: <http://www.infoescola.com/reacoesquimicas/pirolise/> Acesso em: 05 de nov. 2018.

JORDÃO, E. P..; PESSÔA, C. A. Tratamento de Esgotos 
Domésticos. 4. ed. Rio de Janeiro: ABES, 2005. 932 p.

LUTZ, H.; ROMEIRO, G. A.; DAMASCENO, R. N.; KUTUBUDDIN, M.; BAYER, E. Low temperature conversion of some Brazilian municipal and industrial sludges. Bioresource Technology, v. 74, n. 2, p. 103-107, 2000

MARTINS, C. B. M.; QUONIAM, L.; HIRATA, D.; KNIESS, C. T. Informações sobre patentes na área de valorização de resíduos industriais: $\mathrm{O}$ caso do lodo de tratamento de esgoto doméstico. Anais do III SINGEP e II S2IS. São Paulo: Ed. Nove, n.327, 24 nov. 2015. 13 p.

MENEDEZ, J.A.; DOMINGUEZ, A.; INGUANZO, M.; PIS, J. J. Microwave pyrolysis of sewage sludge: analysis of the gas fraction. Journal of Analytical and Applied Pyrolysis, Oviedo, 14 December 2003. 71, p. 657 - 667.

MOREIRA, R. S. Aplicação de lodo de esgoto em latossolo distrófico: fertilidade e disponibilidade de metais pesados. 2013. 48f. Trabalho de conclusão de curso (Graduação) - Universidade Federal de Alfenas, Alfenas, 2013.

OLIVEIRA, J. D.; LOPES, J. C.; ALEXANDRE, R. S.; JASPER, A. D. S.; SANTOS, L. D. S.; OLIVEIRA, L. D. Efeito do lodo de esgoto no desenvolvimento inicial de duas cultivares de mamona em dois tipos de solos. Engenharia Ambiental, v. 6, p. 174-180, 2009.

OLIVEIRA, A. G. Estudo das propriedades mecânicas do lodo tęxtil para fins de utilização em pavimentos rodoviários. 2014. 97 f. Dissertação (Mestrado em Geotecnica) - Universidade Federal de Campina Grande, Campina Grande, 2014.

POKORNA, E.; POSTELMANS, N.; JENICEK, P.; SCHREURS, S.; CARLEER, R.; YPERMAN, J. Study of bio-oils and solids from flash pyrolysis of sewage sludges. Fuel, v. 88, n. 8, p. 1344-1350, 2009.

RODRIGUES, L. S.; FONTES, D. O.; VON SPERLING, M.; OLIVEIRA, P. R.; GOULART, D. B.; SILVA, I. J.; SANTOS, R. L. Avaliação de desempenho de lagoa de polimento para pós-tratamento de reator anaeróbio de manta de lodo (UASB) no tratamento de águas residuárias de suinocultura. Arq. bras. med. vet. zootec, v. 61, n. 6, p. 1428-1433, 2009.

ROMDHANA, M. H.; HAMASAIID, A.; LADEVIE, B.; LECOMTE, D. Energy valorization of industrial biomass: Using a batch frying process for sewage sludge. Bioresource technology, v. 100, n. 15, p. 37403744, 2009.

SÁNCHEZ, M. E.; MENÉNDEZ, J. A.; DOMÍNGUEZ, A.; PIS, J. J.; MARTÍNEZ, O.; CALVO, L. F.; BERNAD, P. L. Effect of pyrolysis temperature on the composition of the oils obtained from sewage sludge. Biomass and Bioenergy, v. 33, n. 6, p. 933-940, 2009.

SANTOS, F. Produção de mudas de Aegiphila sellowiana Cham em diferentes substratos com lodo de esgoto. 2013. 93f . Dissertação (Mestrado em Ciências Florestais)Universidade Federal do Espírito Santo, Vitória, 2013.

SHIMAMURA, M.; NISHIYAMA, T.; SHINYA, K.; KAWAHARA, Y.; FURUKAWA, K.; FUJII, T. Another multiheme protein, hydroxylamine oxidoreductase, abundantly produced in an anammox bacterium besides the hydrazine-oxidizing enzyme. Journal of bioscience and bioengineering, $\mathrm{v}$. 105, n. 3, p. 243-248, 2008.
SILVA, D. P., RUDOLPH, V., TARANTO, O.P. The Drying of Sewage Sludge by Immersion Frying Braz. J. Chem. Eng., São Paulo, 23 April 2005. 22, 271-276.

SILVA, L. C. A. Estudo do processo de pirólise de lodo de esgoto em reator de leito fixo em escala laboratorial. 2012. 66 f. Dissertação (Mestrado em Agroenergia) Universidade Federal do Tocantins, Palmas, 2012.

SPLIETHOFF, H. Solid Fuels, In: SPLIETHOFF, H. Power Generation from Solid Flues. Berlin: Springer, 10 July 2010. 156, p. 15-54.

SURERUS, V.; GIORDANO, G.; TEIXEIRA, L. A. C. Activated sludge inhibition capacity index. Brazilian Journal of Chemical Engineering, v. 31, n. 2, p. 385-392, 2014

TSUTIYA, M. T.; HIRATA, A. Y. Aproveitamento e disposição final de lodos de estações de tratamento de água do estado de São Paulo. In: Congresso Brasileiro de Engenharia Sanitária e Ambiental. 2001. p. 46.

VANZETTO, A. S. Análise das alternativas tecnológicas de desaguamento de lodos produzidos em estações de tratamento de esgoto. 2012. 185 f. Dissertação (Mestrado em Tecnologia Ambiental e Recursos Hídricos) Universidade de Brasília - Brasília/DF, 2012.

VASQUES, A. R. Caracterização de adsorventes obtidos por combustão e pirólise de lodo residual e aplicação no tratamento de efluentes têxteis. Tese (Doutorado em Engenharia Química) - Universidade Federal de Santa Catarina, cidade, 2012.

VIEIRA, G. E. G. Resíduos da produção industrial de borracha (ETRI) e bebida (ETE) - Uma avaliação pela tecnologia de LTC. 2000. 322 p. Dissertação (Mestrado em Agroenergia) - Universidade Federal Fluminense, cidade, 2000

VIEIRA, G. E. G.; PEDROZA, M. M.; SOUSA, J. D.; PEDROZA, C. M. O processo de pirólise como alternativa para o aproveitamento do potencial energético de lodo de esgoto-uma revisão. Revista Liberato, v. 12, n. 17 , p. 81-95, 2011.

VIEIRA, G. R. G.; ALEXANDRE, G. P. Tratamento, caracterização e obtenção de bio-óleo com-bustível a partir da pirólise termocatalítica de lodo de esgoto doméstico-uma revisão. 85f. Dissertação (Mestrado em Agroenergia) - Universidade Federal do Tocantins, Palmas. 2014.

VIEIRA, R. F.; CARDOSO, A. A. Variações nos teores de nitrogênio mineral em solo suplementado com lodo de esgoto. Pesquisa Agropecuária Brasileira, v. 38, n. 7, p. 867-874, 2003.

VIRMOND, E.; SCHACKER, R. L.; ALBRECHT, W.; ALTHOFF, C. A.; DE SOUZA, M.; MOREIRA, R. F.; JOSÉ, H. J. Organic solid waste originating from the meat processing industry as an alternative energy source. Energy, v. 36, n. 6, p. 3897-3906, 2011.

VON SPERLING, M., FERNANDES, F. Lodo de Esgoto: Tratamento e Disposição final. 1. ed. Belo Horizonte: Departamento de Engenharia Sanitária e Ambiental, UFMG, 2001. 484 p.

WERTHER, J.; OGADA, T. Sewage sludge combustion. Progress in energy and combustion science, v. 25, n. 1, p. 55-116, 1999. 